\title{
Biodiesel dari Limbah Pabrik Gula dan Minyak Jarak Pagar (Jatropha curcas) dengan Katalisator Zeolit Alam Klinoptilolite
}

\author{
Ratna Sri Harjanti ${ }^{*}$, Anugrah Perdana Rahmanta ${ }^{2}$ \\ 1,2 Program Studi Teknik Kimia, Politeknik LPP Jl. LPP No. 1A, Balapan Yogyakarta \\ *email: ratna_sh@politeknik-lpp.ac.id
}

\begin{abstract}
The fuel price increase with the increase of the number of transportation due to the increasing numbers of the population. Indonesia with more than 200 million people in need of transportation fuels in the form of gasoline and diesel in large quantities. Currently the main source of transportation fuels derived from petroleum. Premium production in Indonesia is about 62 million barrels and production of about 87 million barrels of diesel fuel. The product does not include the use for other needs, such as lubricating oil, kerosene, avgas, as well as other materials. This is particularly worrying given the oil reserves are dwindling. One of the alternative energy for transportation fuels is biodiesel as a substitute for diesel fuel.The castor oil has potential to be used as biodiesel. Fusel oil is a sugar mill waste containing alcohol. The reaction between castor oil and fusel oil with natural zeolite catalyst klinoptilolite be referred to as alcoholysis reactions that produce esters. Castor oil and fusel oil mixed with zeolite powder klinoptilolite that previously had been heated in a separate place until it reached its boiling temperature. Three neck flask fitted with a thermometer, hoses trailer makers, heater, and the agitator on $100 \mathrm{rpm}$ with $100{ }^{\circ} \mathrm{C}$ of temperature. Snapshot taken at intervals of 30 minutes each. Conversion reaction calculated by analyzing the levels of glycerol bottom layer by means asetin. Alcoholysis fusel oil and castor oil with natural zeolite catalyst klinoptilolite produce esters that are approaching the properties of diesel oil with a calorific value of 19119 Btu/lb. Optimum conversion of $57 \%$ was obtained in alcohol - oil ratio of 9.29 mgek/mgek and the addition of a catalyst as much as $2.56 \%$ of the weight of oil.
\end{abstract}

Keywords: biodiesel, castor oil, fusel oil, alcoholysis

\section{Pendahuluan}

Indonesia dengan jumlah penduduk mencapai lebih dari 200 juta jiwa membutuhkan bahan bakar transportasi dalam jumlah yang besar. Saat ini sumber utama bahan bakar tersebut adalah minyak bumi, sedangkan cadangan minyak bumi kita semakin menipis. Salah satu energi alternatif untuk bahan bakar transportasi adalah bioethanol sebagai pengganti bensin dan biodiesel sebagai pengganti solar.

Komoditas perkebunan penghasil minyak nabati yang dapat dimanfaatkan sebagai bahan baku biodiesel cukup banyak, diantaranya minyak kelapa sawit, kelapa, minyak jagung, dan minyak jarak pagar. Minyak nabati yang memberikan peluang untuk dikonversi menjadi biodiesel dalam jumlah yang besar adalah minyak jarak pagar karena merupakan non edible oil dan tumbuhan jarak pagar dapat hidup dengan mudah di berbagai tempat [1].

Pabrik gula banyak menghasilkan limbah, yang apabila tidak diolah akan menyebabkan pencemaran lingkungan. Salah satu limbahnya adalah minyak fusel yang banyak mengandung alkohol. Pada proses pembuatan gula tebu, Setiap 1 gram glukosa menghasilkan 0,51 gram etanol. Hasil samping yang terbentuk antara lain: asetaldehid (sebagian kecil eter) dan minyak fusel, yang merupakan campuran senyawa alkohol tingkat tinggi dengan komposisi tergantung bahan baku. Laju produksi asetaldehid sekitar 1 liter setiap 1000 liter etanol, dan laju produksi minyak fusel 5 liter/1000 liter alkohol [2]. Karena komponen terbesarnya adalah alkohol, maka reaksi antara minyak jarak dengan minyak fusel, selanjutnya dapat disebut reaksi alkoholisis. Hasil reaksi alkoholisis tersebut adalah gliserol dan ester yang memiliki sifat mirip dengan minyak diesel. Selama ini beberapa penelitian untuk membuat biodiesel dari minyak jarak telah dilakukan, namun masalah utama yang dihadapi adalah kesulitan dalam pemisahan hasil. Berbeda alkholisis minyak nabati lain, hasil alkholisis minyak jarak sulit dipisahkan antara fase ester dengan gliserolnya, apalagi jika di dalam ester tersebut masih terdapat katalisator yang terikut, hal ini akan mempengaruhi kemurnian biodiesel [3].

Zeolit merupakan salah satu katalisator padat yang terdiri dari kristal alumino silikat terhidrasi yang mengandung kation alkali atau alkali tanah. Struktur zeolit berupa kristal polimer anorganik dengan kerangka tetrahedral $\mathrm{AlO}_{4}$ dan $\mathrm{SiO}_{4}$. Rumus struktur zeolit dapat dituliskan sebagai $\mathrm{M}_{\mathrm{x} / \mathrm{n}}\left[\left(\mathrm{AlO}_{2}\right)_{\mathrm{x}} .\left(\mathrm{SiO}_{2}\right)_{\mathrm{y}}\right.$ 
. $\mathrm{wH}_{2} \mathrm{O}$ ], dengan $\mathrm{n}$ adalah valensi dari kation $\mathrm{M}$, w adalah jumlah molekul air per unit sel, $\mathrm{x}$ dan y adalah total jumlah tetrahedral per unit sel [4]. Katalis yang sering digunakan dalam alkoholisis minyak nabati adalah natrium hidroksida [5], dengan menyisipkan logam natrium pada zeolit akan memberikan sifat katalitik yang sesuai sehingga dapat meningkatkan kecepatan reaksi alkoholisis [2].

Penggunaan katalisator padat pada proses alkoholisis diharapkan dapat meningkatkan kemurnian ester karena katalis padat lebih mudah dipisahkan dari pada katalis cair. Salah satu jenis katalisator padat adalah zeolit alam klinoptilolite. Dengan pertimbangan kemudahan dalam pemisahan sisa katalis dari ester yang terbentuk, maka dilakukan penelitian tentang alkoholisis minyak jarak dengan katalisator zeolit klinoptilolite dalam labu leher tiga yang dilengkapi dengan pengaduk dan termometer.

Manfaat dari penelitian yang dilakukan adalah dapat memberikan pengetahuan pada peneliti dan masyarakat umum tentang kondisi optimum reaksi alkoholisis minyak jarak oleh minyak fusel dengan katalisator zeolite alam klinoptilolite dengan ruang lingkup variasi perbandingan katalisator dan variasi perbandingan pereaksi minyak jarak-minyak fusel dalam berbagai waktu. Ester yang dihasilkan diuji sifat fisisnya untuk mengetahui kemungkinannya memiliki sifat mendekati dengan minyak diesel.

\section{Metodologi}

Minyak jarak dimasukkan dalam labu leher tiga kemudian dimasukkan minyak fusel dan zeolit yang telah dipanaskan dalam tempat terpisah sampai mencapai titik didihnya. Zeolit yang digunakan adalah zeolit alam klinoptilolite yang berasal dari Lampung, zeolit ini diaktifkan dengan merebusnya di dalam larutan $\mathrm{NaOH} 1 \mathrm{~N}$ selama 3 jam pada suhu $100{ }^{\circ} \mathrm{C}$ dan mempunyai harga KPK 2,25 meq/gram zeolit. Minyak fusel yang digunakan berasal dari Pabrik Gula Madukismo dengan rapat massa 0,8264 g/mL.

Labu leher tiga dilengkapi dengan pendingin balik dan termometer untuk mengontrol suhu reaksi. Suhu reaksi dijaga konstan $100{ }^{\circ} \mathrm{C}$ dengan putaran pengaduk $100 \mathrm{rpm}$. Cuplikan diambil pada setiap selang waktu 30 menit. Lapisan bawah dianalisis kadar gliserolnya dengan cara asetin. Esternya dianalisa secara ASTM.
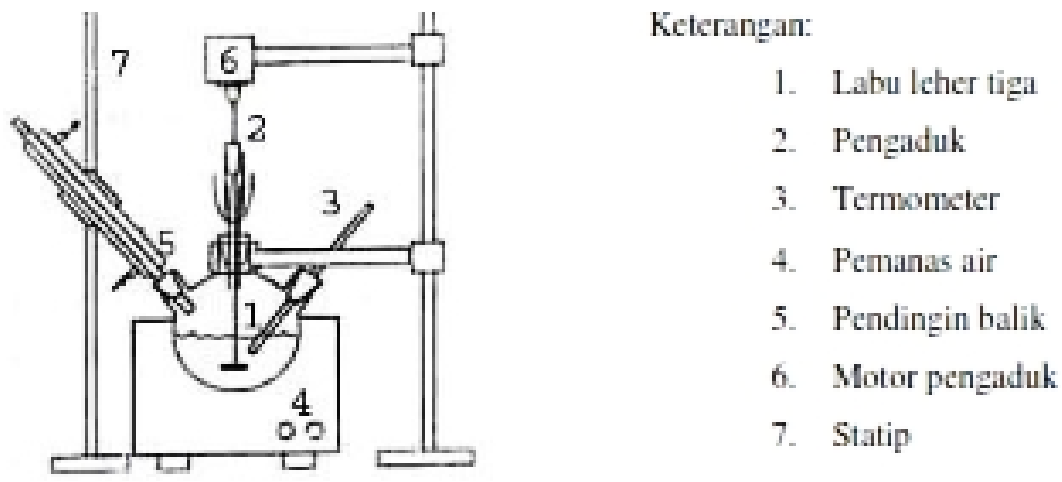

Gambar 1. Rangkaian alat penelitian

\section{Hasil Penelitian dan Pembahasan}

\section{Pengaruh Prosentase Katalisator}

Pengaruh prosentase katalisator dipelajari pada kisaran 1 - 4\% berat minyak, dan peubah yang lain dijaga tetap, yaitu kecepatan pengadukan $100 \mathrm{rpm}$, suhu $100^{\circ} \mathrm{C}$, dan perbandingan alkohol-minyak 9,29 gek/gek.

Tabel 1. $\mathrm{Na}^{+}$yang Terikat dalam Katalisator

\begin{tabular}{cc}
\hline $\begin{array}{c}\text { Prosentase Katalisator } \\
(\% \text { Berat Minyak) }\end{array}$ & $\mathrm{Na}^{+}$yang Terikat (meq) \\
\hline 1,60 & 2,2882 \\
2,14 & 3,0604 \\
2,56 & 3,6611 \\
3,06 & 4,3761 \\
3,56 & 5,0912 \\
\hline
\end{tabular}

Zeolit yang akan digunakan sebagai katalisator, sebelumnya diaktifkan dengan $\mathrm{NaOH}$ sehingga mengikat ion $\mathrm{Na}^{+}$. Hal ini menyebabkan semakin banyak katalisator yang digunakan, semakin banyak pula 
ion $\mathrm{Na}^{+}$yang ditambahkan ke dalam larutan, sehingga proton yang dimiliki alkoxide juga semakin banyak. Banyaknya proton yang dimiliki menyebabkan alkoxide semakin asam (menurut Bronsted), sehingga penyerangan gugus karbonil menjadi semakin cepat dan konversi gliserid yang dihasilkan juga semakin besar [6].

Pada struktur zeolit, semua atom Al dalam bentuk tetrahedral sehingga atom Al akan bermuatan negatif karena berkoordinasi dengan atom oksigen. Zeolit dapat dimanipulasi dengan menyisipkan logam tertentu sehingga memiliki sifat katalitik tertentu [3]. Zeolit alam yang diaktifkan dengan $\mathrm{NaOH}$ akan bersifat basa dan mengikat ion $\mathrm{Na}^{+}$, sehingga sering disebut Na-zeolit $\left(\mathrm{O}-\mathrm{Na}^{+}\right)$. Mekanisme reaksi yang terjadi di dalam reaksi alkoholisis minyak jarak dengan katalisator Na-zeolit, adalah sebagai berikut:

1. Pengaktifan alkohol oleh zeolit

$$
\begin{aligned}
& \stackrel{\mathrm{O}}{\mathrm{O}}^{-} \mathrm{Na}^{+}+\mathrm{R}^{-} \ddot{\ddot{\mathrm{OH}}} \rightarrow \underset{\mathrm{O}}{\mathrm{O}-\mathrm{H}}+\mathrm{R}^{\prime} \ddot{\mathrm{O}}-\mathrm{Na}^{+} \\
& \text {Na-zeolit alkohol ion } \mathrm{OH}^{-} \text {alkoxide } \\
& \text { R'- } \ddot{\mathrm{O}} \text { : merupakan alkoxide ion } \\
& \mathrm{Na}^{+} \text {: merupakan alkoxide ion }
\end{aligned}
$$

Na-zeolit akan mengaktifkan alkohol membentuk alkoxide. Alkohol mendifusi ke permukaan luar katalis, sehingga terjadi pertukaran ion $\mathrm{H}^{+}$dengan ion $\mathrm{Na}^{+}[7]$.

2. Pengaktifan trigliserid oleh zeolite

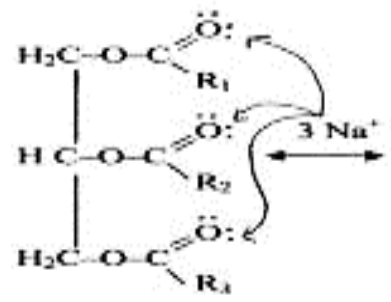

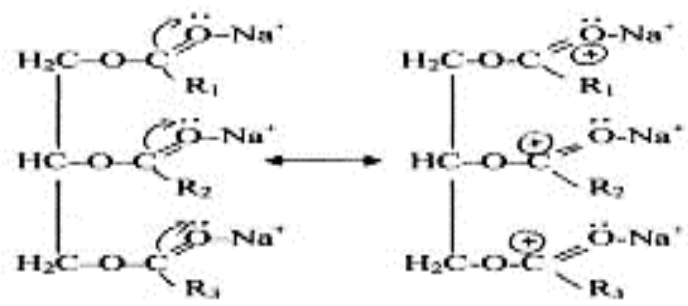

Minyak jarak mendifusi ke permukaan luar katalis, sehingga ion $\mathrm{Na}^{+}$pada zeolit akan mendekati gugus karbonil. $\mathrm{Na}^{+}$akan mencari posisi paling nukleofilik, sehingga $\mathrm{Na}^{+}$akan mendekati $\mathrm{O}$ yang mempunyai dua pasang elektron bebas. Oksigen memberikan satu pasang elektronnya untuk dipakai bersama-sama dengan $\mathrm{Na}^{+}$sehingga oksigen menjadi kekurangan elektron. Karena oksigen bersifat elektronegatif, maka $\mathrm{O}$ akan berusaha menarik pasangan elektron pada ikatan rangkap $\mathrm{C}$. Oleh karena atom $\mathrm{C}$ telah memberikan sebagian elektronnya untuk dipakai bersama $\mathrm{O}$, maka $\mathrm{C}$ pada ikatan rangkap menjadi bermuatan positif (disebut carbocation atau $\mathrm{C}^{+}$) [7].

\section{Pembentukan Ester}

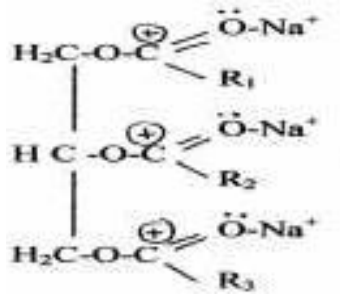

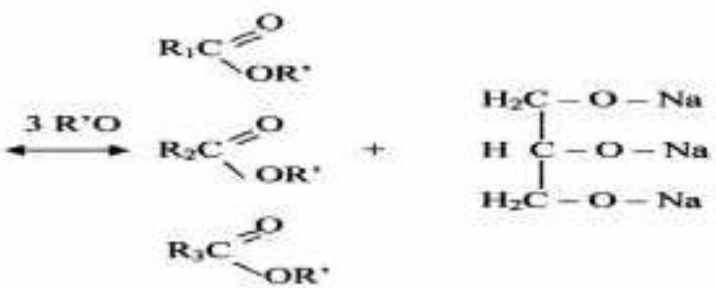

Pencampuran antara zeolit dengan minyak jarak dan minyak fusel (alkohol), akan mengaktifkan minyak jarak dan alkohol oleh ion $\mathrm{Na}^{+}$. Kemudian alkohol yang teraktifkan akan bereaksi dengan minyak jarak yang sudah teraktifkan. Alkoxide memiliki ion R'- $\mathrm{O}^{-}$yang merupakan alkoxide ion dengan dua pasang elektronnya, sedangkan trigliserid yang teraktifkan mempunyai atom $C$ yang bermuatan positif, sehingga R'$\mathrm{O}^{-}$cenderung mendekati atom $\mathrm{C}$ untuk memberikan satu pasang elektronnya untuk dipakai bersama-sama. Setelah terjadi pengaturan elektron untuk mencapai kesetimbangan muatan (sesuai aturan oktet) maka terbentuk ester [7]. 
4. Pelepasan Na-zeolit

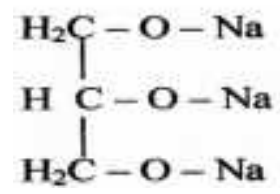<smiles>OCC(O)CO</smiles>

Pada pembentukan alkoxide, terbentuk juga $\mathrm{OH}^{-}$, ion ini akan bertukar tempat dengan ion $\mathrm{Na}^{+}$sehingga terbentuk gliserol. Zeolit dalam bentuk $\mathrm{O}-\mathrm{Na}^{+}$akan terlepas lagi [7]. Zeolit yang telah diaktifkan dengan $\mathrm{NaOH}$, akan mengikat ion $\mathrm{Na}^{+}$, yang mana banyaknya ion $\mathrm{Na}^{+}$ini akan mempengaruhi kualitas alkoxide yang terbentuk, dan berpengaruh terhadap konversi gliserol.

Gliserol yang terbentuk dapat dihitung dengan persamaan [8]:

$$
\mathrm{W}=\frac{\mathrm{W}_{1} \cdot \mathrm{W}_{3}}{\mathrm{~W}_{2} \cdot \mathrm{W}_{4}}\left(\mathrm{~V}_{\mathrm{b}}-\mathrm{V}_{\mathrm{c}}\right) \mathrm{N}_{0}
$$

Besar konversi gliserol adalah [7]:

$$
\mathrm{X}=\frac{\mathrm{W}}{\mathrm{W}_{0}}
$$

Tabel 2. Pengaruh penambahan katalisator $\left(\mathrm{N}=100 \mathrm{rpm}, \mathrm{P}=1 \mathrm{~atm}, \mathrm{R}=9,29 \mathrm{mgek} / \mathrm{mgek}, \mathrm{T}=100{ }^{\circ} \mathrm{C}\right)$

\begin{tabular}{cccccc}
\hline \multirow{2}{*}{ Waktu, menit } & \multicolumn{5}{c}{ Konversi (bagian) pada berbagai prosentase katalisator } \\
\cline { 2 - 6 } & 1,60 & 2,14 & 2,56 & 3,00 & 3,56 \\
\hline 30 & 0,32 & 0,34 & 0,37 & 0,38 & 0,39 \\
60 & 0,40 & 0,41 & 0,43 & 0,46 & 0,48 \\
90 & 0,42 & 0,48 & 0,50 & 0,56 & 0,58 \\
120 & 0,47 & 0,53 & 0,57 & 0,62 & 0,64 \\
\hline
\end{tabular}

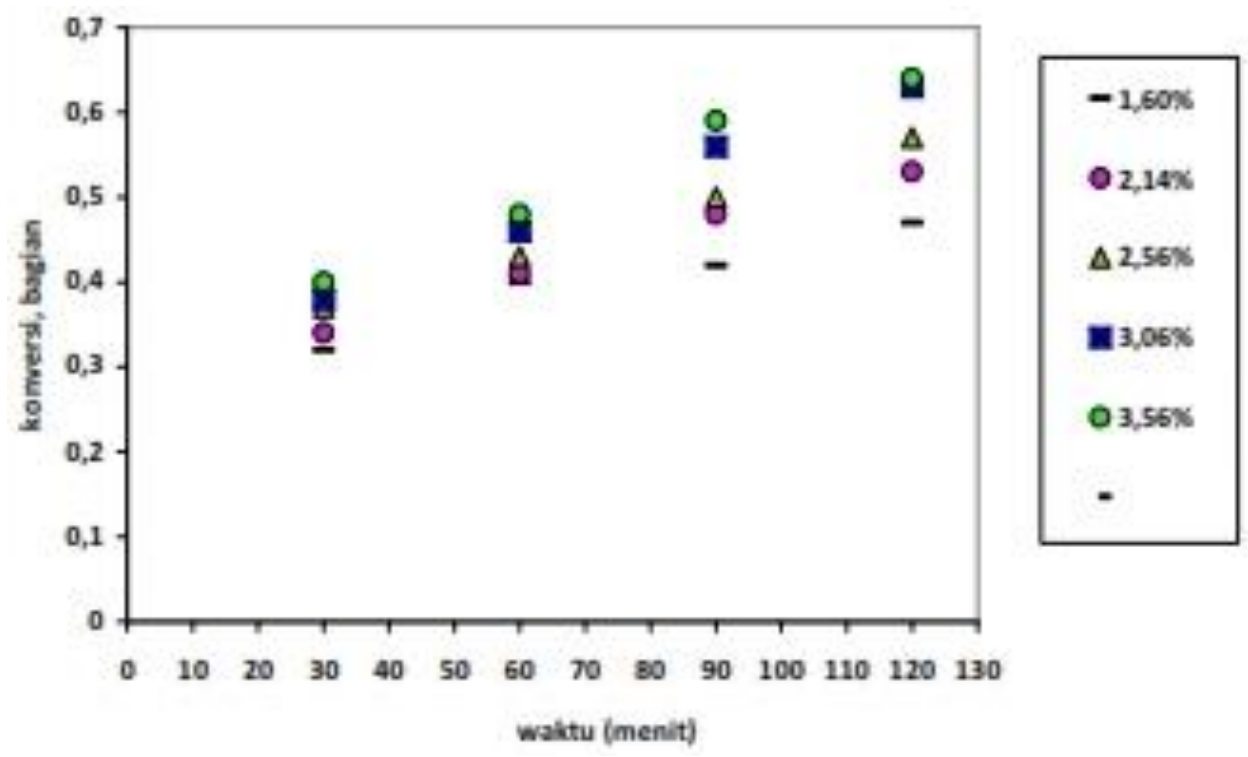

Gambar 2. Hubungan antara waktu (menit) dengan konversi (bagian) pada berbagai persentase katalisator

Tabel 2 dan gambar 2 menunjukkan, semakin banyak katalisator yang ditambahkan ke dalam larutan, semakin besar pula konversi reaksinya. Hal ini disebabkan karena katalisator zeolit yang ditambahkan akan mengaktifkan minyak jarak dan minyak fusel yang dalam hal ini masih banyak mengandung alkohol. Alkohol inilah yang nantinya berperan dalam reaksi alkoholisis. Dengan bertambahnya katalisator, maka 
minyak jarak dan alkohol (minyak fusel) yang teraktifkan juga akan semakin banyak, sehingga memudahkan jalannya reaksi antara minyak jarak dengan alkohol (minyak fusel). Namun ternyata pada batas konsentrasi tertentu, konversi cenderung tetap walaupun konsentrasi katalis ditambah. Hal ini dapat dijelaskan sebagai berikut: pada konsentrasi katalis yang terlalu tinggi, jumlah $\mathrm{Na}^{+}$yang tersedia berlebih dibanding dengan pereaksi yang ada, sehingga walaupun jumlah katalis ditambah, tidak akan meningkatkan konversi.

\section{Pengaruh Perbandingan Pereaksi Minyak Fusel-Minyak Jarak}

Minyak Fusel yang digunakan banyak mengandung alkohol, sehingga dalam reaksi alkoholisis ini yang banyak berperan dari kandungan minyak fusel adalah alkoholnya. Alkohol mempunyai berat molekul yang lebih rendah daripada minyak jarak, sehingga alkohol lebih mudah teraktifkan oleh ion $\mathrm{Na}^{+}$yang dibawa katalisator zeolit. Semakin banyak alkohol yang teraktifkan, diharapkan dapat memperbesar konversinya, sehingga perlu dilakukan penelitian dengan mengubah-ubah perbandingan pereaksi alkohol (minyak fusel) minyak jarak.

Tabel 3. Pengaruh perbandingan ekivalen minyak fusel-minyak jarak $\left(\mathrm{N}=100 \mathrm{rpm}, \mathrm{P}=1 \mathrm{~atm}, \mathrm{~K}=2,56 \%, \mathrm{~T}=100{ }^{\circ} \mathrm{C}\right)$

\begin{tabular}{cccccc}
\hline \multirow{2}{*}{ Waktu, menit } & \multicolumn{5}{c}{ Konversi (bagian) pada berbagai prosentase katalisator } \\
\cline { 2 - 6 } & 2,56 & 3,98 & 5,97 & 9,29 & 15,93 \\
\hline 30 & 0,25 & 0,28 & 0,32 & 0,37 & 0,39 \\
60 & 0,27 & 0,30 & 0,35 & 0,43 & 0,44 \\
90 & 0,35 & 0,38 & 0,44 & 0,50 & 0,52 \\
120 & 0,40 & 0,45 & 0,50 & 0,57 & 0,58 \\
\hline
\end{tabular}

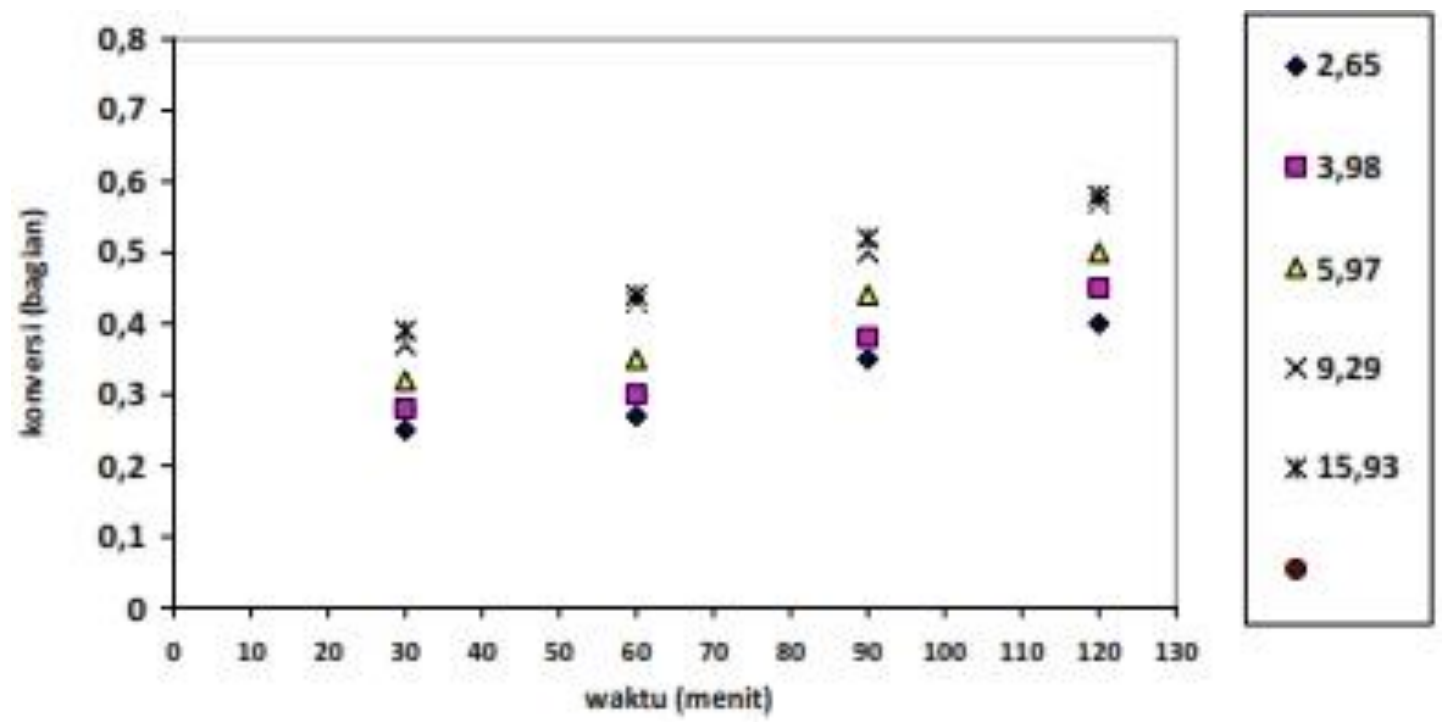

Gambar 3. Hubungan antara waktu (menit) dengan konversi (bagian) dalam berbagai perbandingan ekivalen minyak fusel-minyak jarak (gek-gek)

Tabel 3 dan gambar 3 menunjukkan kenaikan konversi reaksi dengan bertambahnya perbandingan ekivalen minyak fusel -minyak jarak. Semakin banyak munyak fusel yang digunakan, dalam hal ini semakin banyak banyak pula alkohol yang digunakan, maka semakin banyak senyawa alkoxide yang terbentuk, semakin besar pula konversi reaksinya. Semakin besar perbandingan ekivalen alkohol-minyak, maka kemungkinan etanol yang teraktifkan oleh zeolit akan semakin besar dan tumbukan antara zatzat pereaksi juga semakin besar, sehingga konversi semakin besar. Katalisator zeolit sebanyak 2,56\% berat minyak, apabila ditambahkan pada larutan alkohol minyak yang mempunyai perbandingan ekivalen 9,29 mgek/mgek , akan memberikan konversi yang lebih besar daripada penambahan pada perbandingan 5,97 mgek/mgek. Hal ini disebabkan pada perbandingan ekivalen miyak fusel-minyak jarak 9,29 mgek/mgek pembentukan senyawa alkoxide lebih banyak karena mengandung lebih banyak alkohol pada minyak fusel. Senyawa alkoxide inilah yang akan bereaksi dengan trigliserid membentuk ester dan gliserol. Namun pada 
perbandingan alkohol-minyak yang lebih tinggi lagi ternyata kenaikan konversi reaksi tidak besar, bahkan cenderung tetap, sehingga kondisi yang relatif baik pada perbandingan 9,29 mgek/mgek.

Konversi hasil yang diperoleh masih sangat rendah, hanya sekitar 57\%, hal ini dapat ditingkatkan dengan menaikkan tekanan operasinya, yaitu reaksi dijalankan pada autoklaf sehingga tekanan dapat dinaikkan. Apabila tekanan lebih tinggi daripada 1 atm, maka suhu operasi bisa lebih tinggi lagi. Sesuai dengan Arrhenius, semakin tinggi suhu maka kecepatan reaksinya akan semakin tinggi.

\section{Pengolahan Hasil}

Ditinjau dari berat jenisnya, ester dari minyak jarak memiliki berat jenis di antara batas minimum dan maksimum minyak diesel. Apabila dilihat dari titik tuangnya yang sangat rendah, hal ini berarti bahwa biodiesel hasil dari penelitian ini dapat digunakan pada daerah yang sangat dingin. Dan apabila dilihat dari titik nyalanya, penyimpanan ester dari minyak jarak tidak terlalu beresiko karena menyala pada suhu yang sangat tinggi, sehingga apabila ditinjau dari segi kemanannya sangat baik. Ditinjau dari nilai kalornya, ester ini memberikan nilai kalor di atas batas minimum yang dianjurkan dalam spesifikasi minyak diesel.

Tabel 4. Spesifikasi minyak diesel, minyak jarak, dan ester dari minyak jarak-minyak fusel

\begin{tabular}{ccccc}
\hline Sifat & $\begin{array}{c}\text { Minyak diesel } \\
(\text { minimum })\end{array}$ & $\begin{array}{c}\text { Minyak Diesel } \\
(\text { maksimum) }\end{array}$ & Minyak Jarak & $\begin{array}{c}\text { Ester dari minyak } \\
\text { jarak- minyak fusel }\end{array}$ \\
\hline $\begin{array}{c}\text { Berat jenis, } 60^{\circ} \mathrm{F} \\
\text { Kekentalan Redwood }\end{array}$ & 0,84 & 0,92 & 0,9582 & 0,9202 \\
pada $100^{\circ} \mathrm{F}$, detik & 35 & 45 & 1115 & 80 \\
Titik tuang, ${ }^{\circ} \mathrm{F}$ & - & 65 & 55 & $-16,6$ \\
Titik nyala, ${ }^{\circ} \mathrm{F}$ & 150 & - & - & 215 \\
Warna ASTM & 6 & - & 0,5 & 1 \\
Nilai kalor, Btu/lb & 19120 & - & 18822 & 19119 \\
\hline
\end{tabular}

\section{Kesimpulan}

1. Kondisi optimum dalam alkoholisis minyak jarak oleh minyak fusel dengan katalisator zeolite alam klinoptilolite adalah pada perbandingan minyak jarak-minyak fusel 9,29 mgek/mgek dan penambahan katalisator 2,56\% akan diperoleh konversi sebesar 57\%.

2. Zeolit alam klinoptilolite dapat digunakan sebagai katalisator reaksi alkoholisis.

3. Pembuatan biodiesel dari minyak jarak dan minyak fusel dengan katalisator zeolit klinoptilolite adalah salah satu usaha mengatasi masalah kenaikan harga bahan bakar minyak menggunakan bahan-bahan yang telah banyak tersedia di alam Indonesia sendiri.

\section{Daftar Notasi}

$\mathrm{W}=$ gliserol yang terbentuk, mgek

$\mathrm{W}_{\mathrm{o}}=$ jumlah gliserol teoritis pada bahan baku, mgek

$\mathrm{W}_{1}=$ berat total campuran pada awal reaksi, gram

$\mathrm{W}_{2}=$ berat cuplikan yang diambil, gram

$\mathrm{W}_{3}=$ berat lapisan gliserol, gram

$\mathrm{W}_{4}=$ berat lapisan gliserol yang dianalisis, gram

$\mathrm{Vb}=$ volume $\mathrm{HCl}$ untuk titrasi blangko, $\mathrm{mL}$

$\mathrm{Vc}=$ volume $\mathrm{HCl}$ untuk titrasi cuplikan yang dianalisis, $\mathrm{mL}$

$\mathrm{No}=$ konsentrasi $\mathrm{HCl}, \mathrm{mgek} / \mathrm{mL}$

$\mathrm{N}=$ kecepatan putaran autoklaf, rpm

$\mathrm{K}$ = perbandingan ekivalen etanol-minyak, mgek/mgek

\section{Daftar Pustaka}

[1] Harjanti, R.S., 2009. Alkoholisis Minyak Jarak dengan Katalisator Zeolit Alam Klinoptilolite Secara Batch pada Suhu di Atas Titik Didih Etanol, Tesis, Universitas Gadjah Mada, Yogyakarta, Indonesia.

[2] Maiorella, B.L. 1985. Ethanol Fermentation. Comprehensive Biotechnol. Young M (ed), Pergamon Press Oxford. Vol 3, pp.861-914.

[3] Hambali, E., dkk, 2006. Jarak Pagar Tanaman Penghasil Biodiesel. Penebar Swadaya, Jakarta.

[4] Haslego, C., 1999. Green Chemistry with Zeolite Catalyst, www.cheresources.com, diakses 20 Februari 2009. 
[5] Kirk, R.E., and Othmer, D.F., 1979. Encyclopedia of Chemical Thecnology. vol.5, pp.817-819, Interscience Encyclopedia, Inc., New York.

[6] Liu, X, Piao, X, Wang, Y and Zhu, S, 2008. Calsium Ethoxide as a Solid Base Catalyst for The Transesterification of Soybean Oil to Biodiesel. Energy \& Fuels 22: 1313-1317.

[7] Serio, M.D., Teseer, R., Pengmei, and Santacesaria, 2008. Heterogeneous Catalyst for Biodiesel Production. Energy \& Fuel, 22: 207-217.

[8] Griffin, R.C., 1995. Technical Methods of Analysis. 2 ed., pp. 107-110, Mc Graw Hill Book Company, Inc., New York. 